\title{
Prediction of the Oscillatory Heat Transfer Coefficient in Thermoacoustic Refrigerators
}

\author{
Mosa Machesa, Lagouge Tartibu*(D) and Modestus Okwu \\ Department of Mechanical \& Industrial Engineering Technology, Faculty of Engineering and the Built \\ Environment, University of Johannesburg, Johannesburg 2028, South Africa; mosamachesa@gmail.com (M.M.); \\ mechanicalmodestus@yahoo.com (M.O.) \\ * Correspondence: 1tartibu@uj.ac.za
}

Citation: Machesa, M.; Tartibu, L.; Okwu, M. Prediction of the Oscillatory Heat Transfer Coefficient in Thermoacoustic Refrigerators. Sustainability 2021, 13, 9509. https:// doi.org/10.3390/su13179509

Academic Editor: Amir Mosavi

Received: 29 May 2021

Accepted: 16 August 2021

Published: 24 August 2021

Publisher's Note: MDPI stays neutral with regard to jurisdictional claims in published maps and institutional affiliations.

Copyright: (c) 2021 by the authors. Licensee MDPI, Basel, Switzerland. This article is an open access article distributed under the terms and conditions of the Creative Commons Attribution (CC BY) license (https:// creativecommons.org/licenses/by/ $4.0 /)$.
Abstract: Thermoacoustic refrigerators are emerging devices that make use of meaningful highpressure sound waves to induce cooling. Despite the accelerated progress in the field of thermoacoustics, knowledge of the heat transfer process in the heat exchange of the devices is still developing. This work applies different soft computing techniques, namely, an artificial neural network trained by particle swarm optimisation (ANN-PSO), adaptive neuro-fuzzy inference system (ANFIS), and artificial neural networks (ANNs) to predict the oscillatory heat transfer coefficient in the heat exchangers of a thermoacoustic device. This study provides the details of the parametric analysis of an artificial neural network model trained by particle swarm optimisation. The solution model considers the number of neurons, the swarm population, and the acceleration factors to develop and analyse the architecture of several models. The regression model $\left(R^{2}\right)$ and mean squared error (MSE) were used to evaluate the accuracy of the models. The result showed that the proposed soft computing techniques can potentially be used for the modelling and the analysis of the oscillatory heat transfer coefficient with a higher level of accuracy. The result reported in this study implies that the prediction of the OHTC can be considered for the enhancement of thermoacoustic refrigerators performances.

Keywords: thermoacoustics; soft computing techniques

\section{Introduction}

Traditional ways of refrigeration have played an important role in modern life. The traditional refrigeration process is stimulated by the vapour compression cycle that utilises certain refrigerants. Since its introduction at the dawn of the nineteenth century, the structure of the refrigeration system has undergone several developments [1]. Even though there have been numerous developments, the traditional refrigeration system presents a great threat to the earth through its generation of greenhouse gases that deplete the ozone layer. Gases such as fluorine, carbon, and chlorine are blended to obtain the correct refrigeration temperature, which has proven its potential to contribute to global warming [1]. The construction of the traditional system also involves significant energy costs. An analysis of the disadvantages of traditional refrigerators has led to efforts to move away from their use. Thermoacoustic refrigeration is an excellent substitute, as it has shown the potential to provide cooling without any negative impact on the environment at a relatively low cost.

Thermoacoustics is the science of the interaction between thermodynamics and the oscillatory stream of sound waves when introduced to a temperature gradient. The movement of the working gas causes variations in the pressure and initiates the heat transfer between the walls of the regenerator to begin the thermoacoustic cycle [2]. Two distinct thermoacoustic systems exist. Thermoacoustic refrigerators use high-amplitude sound waves to pump heat from one point to another and thermoacoustic engines use heat energy to generate sound waves that are typically used to power the thermoacoustic refrigerators. 
Utilising substandard energy, operating with pro-green materials and no harmful refrigerants, functioning with limited moving parts, and using air as the working gas are some of the key leverage factors that thermoacoustic devices have over their counterparts [3]. Despite the major progress achieved in the field of thermoacoustic refrigeration over recent years, the fundamental theory of the technology has not yet been entirely established. Design and performance issues have been reported by several researchers. Engineering and the selection of the heat exchanger parameters in the device have posed a particular challenge [4].

Originally, thermoacoustic theories were formed on the foundation of phonetic theories, and further developments were based on linear theories [5]. To date, the theories are not fully comprehended because of the limited practical work done in the field. Researchers have been utilising numerical modelling to better understand thermoacoustic theories. The process of numerically modelling thermoacoustic devices has proven to be a tedious procedure that requires extraordinarily complex representations. In addition, although the established linear theory has been widely used to model and represent thermoacoustic devices, it is not able to characterise non-linear relationships in thermoacoustic devices [5].

A heat exchanger's purpose in the thermoacoustic device is to interchange heat with external sources and sustain an extreme temperature gradient through the stack to promote a healthy thermoacoustic cycle [6]. The application of thermoacoustic-based heat exchangers in refrigeration has shown considerable promise. Nonetheless, the process involving heat exchanges and thermoacoustic stacks has shown severe complexities. The impact of various heat exchanger geometrical variables, such as heat exchanger length, fin spacing, and the gap between heat exchangers and stacks, on the heat transfer process and oscillatory heat transfer coefficient (OHTC) is not fully understood [5]. Oscillating flow is a typical process in the operation of thermoacoustic refrigerators where the working gas follows an intermittent oscillatory wave. The oscillatory flow in a heat exchanger is considered to be one of the significant elements in thermoacoustic devices and can influence the entire efficiency of devices following the thermoacoustic stack [3]. With further progression in the field, the heat transfer in oscillatory heat exchangers was established as a barrier in the process of transferring the thermoacoustic heat flow.

Bensoin and Knio studied the influence that varying the geometrical configuration had on the oscillatory heat transfer of heat exchangers in the flow [7]. The researchers used plate-fin heat exchangers and varied parameters, including the length of the heat exchanger, the space between the exchanges, fin spacing and plate stacks. The integration of thermoacoustic heat exchangers in refrigeration systems has demonstrated positive results in terms of the feasibility of the systems. Matveev established that the process of the heat exchanger is highly complex and the performance of the heat exchanger and the stack has a great impact on the overall performance of the thermoacoustic refrigerators [8]. Paek et al. conducted studies on the thermal efficiency of a thermoacoustic refrigerator. The researchers simulated heat exchanges that were similar to radiators used in the automotive industry. The correlation of the heat exchanger's heat transfer coefficient was developed by making use of the Colburn J-factor [9].

Wakeland and Keolian presented work exploring the OHTC of a set of heat exchangers. The researchers tested the performance of the heat exchanger under various ranges of frequencies. The experiment was conducted without the stack inserted between the two heat exchangers. This work allowed for the correlation of the heat transfer to be established [10]. Tang et al. studied round-shaped heat exchangers with fins in the centre. The researchers used electrical ejection machining to perform the experiment. The outputs of the experiment established the correlations of the heat transfer process using experimental data samples. The researchers went on to mathematically model the boundary layers and the Reynolds number to assess the experimental results obtained. The results indicated that the oscillation pressure and the frequency are the main variables influencing the OHTC, and they will therefore be studied in the current work [11]. 
Recently, techniques based on artificial intelligence have been broadly applied in various engineering fields, industrial developments, and renewable energy problems. Artificial intelligence (AI) techniques have a natural harmony that can be used to develop prominent computing practices. A common focus of AI is the effort to address inefficiencies in traditional methods [12]. In most instances, the intention is to provide improved systems with enhanced performance. Sensible use of AI techniques leads to beneficial systems with enhanced performance [12]. This work proposes the use of an artificial neural network trained by particle swarm optimisation (ANN-PSO), artificial neuron network (ANN) and adaptive neuro-fuzzy inference system (ANFIS) to predict the heat oscillating flow coefficient of a heat exchanger. The work proposes an alternative technique for obtaining the OHTC values in a thermoacoustic heat exchanger. The parameters such as the number of neurons, swarm population, etc., of the ANN-PSO algorithm are varied to analyse the influence of the ANN-PSO architecture on the accuracy of the prediction of the OHTC in thermoacoustic systems.

The paper is organised in the following manner: Section 2 highlights the background research on thermoacoustic refrigerators. Section 3 describes the experimental procedure undertaken by Nsofor et al. to measure the heat transfer in the heat exchanger. Section 4 presents the application of artificial intelligence in thermoacoustic devices. Section 5 describes the methodology used in the work. Section 6 presents the results and discussion, and the conclusion is presented in Section 7.

\section{General Thermoacoustic Refrigerators}

The thermoacoustic effect is generally defined as the interaction between an acoustic wave, solid objects, and heat energy [3]. For thermoacoustic refrigerators, the propagation of acoustic waves encourages a temperature difference. The thermoacoustic device uses sound waves to pump heat, where the linear alternator's piston is the only part moving. The primary supply of sound energy is referred to as the acoustic driver. A linear alternator or a simple loudspeaker can be used as a driver of a thermoacoustic refrigerator. The acoustic driver's purpose is to release sound waves in the resonator (tube) in the presence of high-pressure gas. Essentially, as the acoustic wave is forced in the gas, the gas molecule experiences repeated vibration, combined with a series of compression and expansion actions. This process is described as the thermoacoustic effect. The process stimulates a change in the temperature on both ends of the stack, where heat flows from one end of the stack to another. An efficient heat exchanger will then be used to control the temperature by removing the heat on the hot heat exchanger and assisting in moving the cooler temperature at the cold end of the stack to perform useful work. The cooling temperature can inherently be applied to refrigeration. The general arrangement of a thermoacoustic refrigerator is seen in Figure 1.

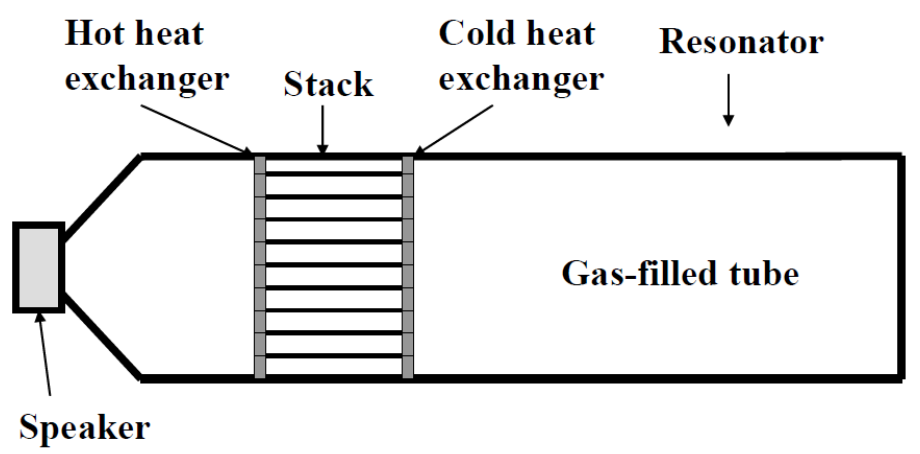

Figure 1. Thermoacoustic refrigerator.

Each element in the thermoacoustic refrigerator plays a significant role in the performance of the thermoacoustic device. 
The cold and hot heat exchangers are placed on the opposite ends of the stack. The heat exchangers are necessary to control the temperature while creating a temperature gradient in thermoacoustic devices. The optimal design of the stack is essential to get the maximum difference in temperatures. Little is known about heat transfer in oscillatory flows with zero mean velocity. The understanding of these flows could potentially contribute meaningfully to the improvement of thermoacoustic system performance [13].

Hofler [14] designed and constructed the first known thermoacoustic refrigerator. The refrigerator used helium as the working fluid. The maximum COP achieved by the device was $12 \%$ of Carnot COP, and the minimum temperature ratio observed was 0.66. Tijani et al. [15] designed and built a thermoacoustic refrigerator driven by a simple loudspeaker. The design was created using design algorithms developed by Herman. Tijani experimentally studied the influence of varying the plate spacing on the performance of the thermoacoustic refrigerator. The experiment revealed that when the plate spacing is double the thermal penetration depth, the greatest heat flux is noticed. Tijani [16] further went on to provide authors with techniques to optimise the driving loudspeaker for a thermoacoustic refrigerator. The lowest reported temperature was $-65^{\circ} \mathrm{C}$.

\section{Experimental Method Used to Measure Oscillatory Heat Transfer}

Research in the oscillatory heat transfer coefficient has been performed as far back as the 1930s by Hausen and co-workers in the analysis of regenerators [17]. Enormous stove systems that consisted of large regenerative exchangers employed in iron processing for furnaces were assessed by the researchers. In today's world, new systems are developed continuously and advancements in the performance of older machinery have become second nature. An important requirement in incorporating design enhancements with respect to the efficiency improvements in the heat exchangers is a well-defined measurement method, yielding high levels of accuracy and swiftness.

The schematic shown in Figure 2 describes the heat transfer that occurs in the heat exchanger fins. Figure 2a shows one enlarged fin and Figure $2 b$ shows the heat balance's control volume. The shaded section in Figure $2 a$ is magnified in Figure $2 b$. The description that follows will detail some of the calculations required to determine the heat transfer in heat exchangers. To determine the optimum length $\left(l_{c}\right)$ of the heat exchanger, the peak-topeak displacement of the working gas is used. The ideal length $l_{c}$ of the heat exchanger ought to be equivalent to the peak-to-peak movement of the working gas. The equation is [18]:

$$
l_{c}=\frac{P_{0}}{a \omega \rho_{m}} \operatorname{Sin}(K l)
$$

where $P_{0}$ represents the dynamic pressure amplitude, $a$ represents the speed of sound, $\omega$ represents the angular frequency, $\rho_{m}$ is the mean density, $K$ represents the wave number, and $l$ represents the displacement.

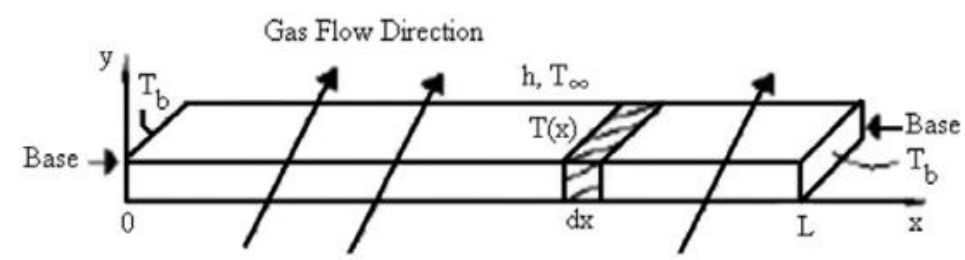

(a) a single fin of the heat exchanger

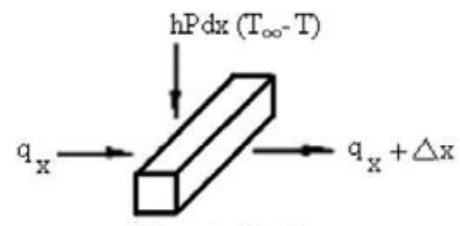

(b) control volume

Figure 2. Section showing heat transfer on the fin of a heat exchanger [18]. 
The energy balance with regards to the heat transfer rate $q$ in the element in Figure $2 b$ is given by:

$$
q_{X}+q_{\text {convection }}=q_{X+\Delta X}
$$

where $X$ is the distance, and $q_{X}$ is the heat transfer rate over a certain distance.

Equation (2) can also be given by:

$$
q_{X}+h P \Delta X\left(T_{\infty}-T\right)=q_{X}+\frac{d q_{X}}{d X} \Delta X
$$

where $h$ is the heat transfer coefficient, $P$ is the perimeter, $T_{\infty}$ is the time-averaged temperature, and $T$ represents the temperature.

After substitution of the heat transfer rate and rearrangement, Equation (3) can be written as follows:

$$
\frac{d^{2} \theta}{d X^{2}}-m^{2} \theta=0
$$

where $\theta$ is the temperature difference. $\theta=T(X)-T_{\infty}$ and $m^{2}=\frac{h P}{k \wedge} . \wedge$ represent the area.

The solution to Equation (4) will then yield Equation (5), given by:

$$
\theta=C_{1} e^{m X}+C_{2} e^{-m X}
$$

where $T_{b}$ is the base temperature of the fins, $L$ is the length of the fin, $C_{1}$ and $C_{2}$ are constants determined by the following boundary conditions.

$$
\begin{gathered}
\text { At } X=0, \theta=T_{b}-T_{\infty}=\theta_{\infty}, \\
\text { At } X=\frac{L}{2}, 0, \frac{d \theta}{d X}=0 .
\end{gathered}
$$

Equation (8) provides for the temperature distribution along the fin. This is accomplished using the boundary conditions given in Equations (6) and (7).

$$
T(X)=T_{\infty}+\frac{T_{b}-T_{\infty}}{1+e^{-\sqrt{\frac{h P}{k \wedge} L}}}\left(e^{\sqrt{\frac{h P}{k \wedge}(X-L)}}+e^{-\sqrt{\frac{h P}{k \wedge} X}}\right)
$$

where: $L$ is the length of the fin, and $k$ is the thermal conductivity.

The experimental procedure to measure the heat transfer in a thermoacoustic heat exchanger was performed by Nsofor et al. [18]. Figure 3 shows the location of the thermocouple sensors used to measure the temperature in the device. A pressure transducer mounted onto the flange of the device was used to measure the dynamic pressure, while the flow measurements were taken with a flow metre. To measure base temperature, $\mathrm{T}_{\mathrm{b}}$ thermocouples were placed at locations 7 and 10 in Figure 3. For the temperature distribution $\mathrm{T}(\mathrm{x})$ measurement, thermocouples were installed along the length of the fin at random locations from the fin. Thermocouples mounted at locations number 9, 12, and 13 measured the temperature distribution. To measure the gas flow's temperature $T_{1}$, thermocouples were placed in locations 8 and 11. The ambient temperature was also measured, and this was done by installing thermocouples between the fins in such a manner that the pointer of the thermocouple did not touch the fins. The thermoacoustic thermocouple located at 1 was placed to monitor the temperature of the acoustic driver. Two thermocouples were mounted to measure the inlet and outlet temperatures of the cooling water. The temperature was also measured at both ends of the stack. The thermocouple range was capable of measuring temperatures between 200 and $300{ }^{\circ} \mathrm{C}$. A board with 16 differential analogue inputs and WaveView for Windows software connected to a computer were used to acquire the data. The resonator was sealed properly and pressurised to test for leakages by using pressures up to 10 bars. Each of the sensors was calibrated before the experiment was performed. Charging of the working gas was done with extra caution to avoid any damage to the cone of the speaker. The system was operated at different frequencies 
for various mean pressures and $\mathrm{h}$ was determined for each case using Equation (8). For accuracy purposes, numerous readings were taken and averaged out for each data point.

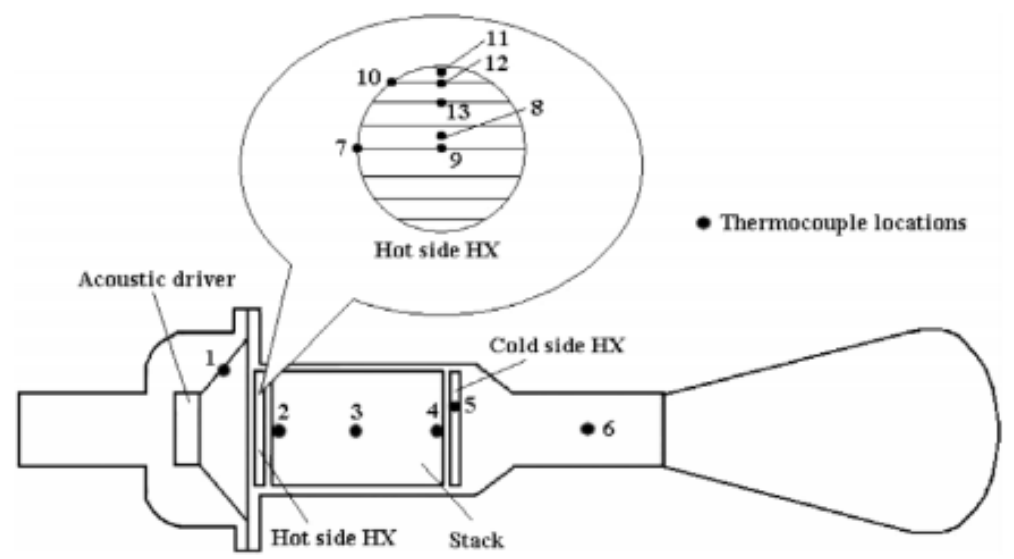

Figure 3. Schematic illustrating the apparatus used in the experimental procedure to measure heat transfer [18].

\section{Artificial Intelligence in Thermoacoustic Devices}

AI models in research related to thermoacoustic devices have been applied in areas of optimising, parameter selection, and output prediction. A summary of the notable studies appears in this section.

\subsection{Selection of Thermoacoustic Parameters}

Precise modelling of thermoacoustic devices is an imperative element in the research and development of thermoacoustic devices. It is common to initially model the device mathematically, then to derive the parameters [19]. Despite a simple geometry, the thermoacoustic device has proven to be significantly challenging, with more than 30 design parameters that heavily influence the performance [20]. Accurate derivation of the parameters is critical in the modelling and sizing of thermoacoustic devices. Many researchers have made use of different conventional techniques to accurately identify thermoacoustic device parameters.

Mumith et al. presented the implementation of a design methodology through the application of Reinforcement Learning (RL) [20]. This design technique allows optimisation through defining and determining excellent and poor behaviour in relation to the acoustic power generated by applying a reward system. The work showed the potential of the RL method to solve parameter selection problems within thermoacoustics. The RL efficiently determined the parameters that enabled the thermoacoustic device to generate a satisfying acoustic output. The thermal efficiency generated from components determined by the RL was $3.29 \%$, with an acoustic power output of $643.31 \mathrm{~W}$.

\subsection{Prediction of Thermal Performance}

$\mathrm{AI}$ algorithms are also used to predict the thermal performance of heat exchangers. The heat exchanger's thermal efficiency is understood as the ratio of the actual heat transfer in a heat exchanger to the optimum heat transfer rate [3]. A higher thermal efficiency essentially means that the thermodynamic cycle can begin with the a lower temperature gradient. Rao and Raju utilised a Regression Neural Network to improve the thermal performance of a heat exchanger. The network used the temperature, the orientation of the angle, and the flow rate as inputs. The outputs of the model were the outlet temperature as well as the pressure drop. The Generalised Regression Neural Network proved to be a quick and accurate method to improve and predict the thermal performance, with less than $2 \%$ error rate between the experimental data and predicted data [21]. 


\subsection{Oscillatory Heat Transfer Coefficient}

$\mathrm{AI}$ algorithms are also used in determining the oscillatory heat transfer coefficient. Most of the established heat transfer relationships cannot be applied to the constant flow design in thermoacoustic devices. The first reason for this is that oscillatory flow conditions of heat exchangers operating in thermoacoustics differ from the flow in conventional heat exchangers. The second reason is that some relationships related to the oscillatory heat transfer coefficient have not yet been conclusively proved by researchers. AI techniques have been employed by various researchers to determine the coefficient. Machesa et al. applied two AI techniques, namely, an adaptive neuro-fuzzy inference system (ANFIS) and an artificial neural network trained by particle swarm optimisation (ANN-PSO), to estimate the heat oscillatory transfer coefficient heat exchanger functioning in a thermoacoustic device. The network's inputs were the mean pressure and oscillating frequency. The networks had one output, characterised by the oscillatory heat transfer coefficient. The work showed that AI techniques are highly appropriate for use in providing targeted output with minimal error [5].

\subsection{Acoustic Impedance Characteristics}

The acoustic impedance is an especially important factor in a thermoacoustic device, as it controls the acoustic power dissipation that essentially determines the electrical outputs [22]. Abdelrahman and Zhang used synergistic neural networks to predict the acoustic pressure amplitude of a thermoacoustic engine simulated using DeltaEC. The work aimed to improve the parameter predicted by DeltaEC [23]. The simulation predominantly considered conditions of the resonator length and stack characteristics. Integrating DeltaEC with synergistic neural networks proved to be successful in providing precise output values. The hybrid model provided more accurate results than the those generated with the DeltaEC model. The researcher further used an ANN model to predict acoustic pressure parameters [3]. Similar conditions to the synergistic neural network were used with the ANN model. The work showed that the ANN model is an effective tool to model the acoustic pressure parameter in a thermoacoustic engine. The ANN model integrated with DeltaEC obtained accurate outputs, with an error rate of $0.78 \%$.

\subsection{Proposed Approach}

The need for reliable methods to accurately unravel unfamiliar pattern relationships and predict unknown data has increased significantly as systems have increasingly become more and more complex over the years. The methodology put forward proposes an evaluation of the prediction performance of ANN-PSO, ANN, and ANFIS by comparing the $\mathrm{R}^{2}$ of the three algorithms. The ANN-PSO algorithm used in this work is from Alam [24]. The measurement criteria used to evaluate the performance of all configurations of the algorithms are the coefficient of determination $\left(R^{2}\right)$ and the mean square error (MSE).

This work further assesses the impact that varying parameters in the ANN-PSO algorithm have on the prediction accuracy of the network. The parameters that varied were the number of neurons, the swarm population size, and the acceleration factors. The workflow used in this work is shown in Figure 4.

The data samples used to train and validate the algorithm are tabulated in Table 1. The tabulated data were consistent with experimental data collected by Nsofor et al. [18]. The work indicated that the optimisation of the OHTC is predominantly dependent on the frequency and mean pressure values. As a result, the inputs of the algorithm were the frequency and the mean pressure. The ranges of the frequency and mean pressure were from 300 to $450 \mathrm{~Hz}$ and 0.303 to $0.81 \mathrm{MPa}$, respectively. The output of the algorithm was the OHTC. The data fed into the algorithm were divided into training and validation. Nineteen of the experimental data values were used for training, while five of the experimental values were used to validate the model. 


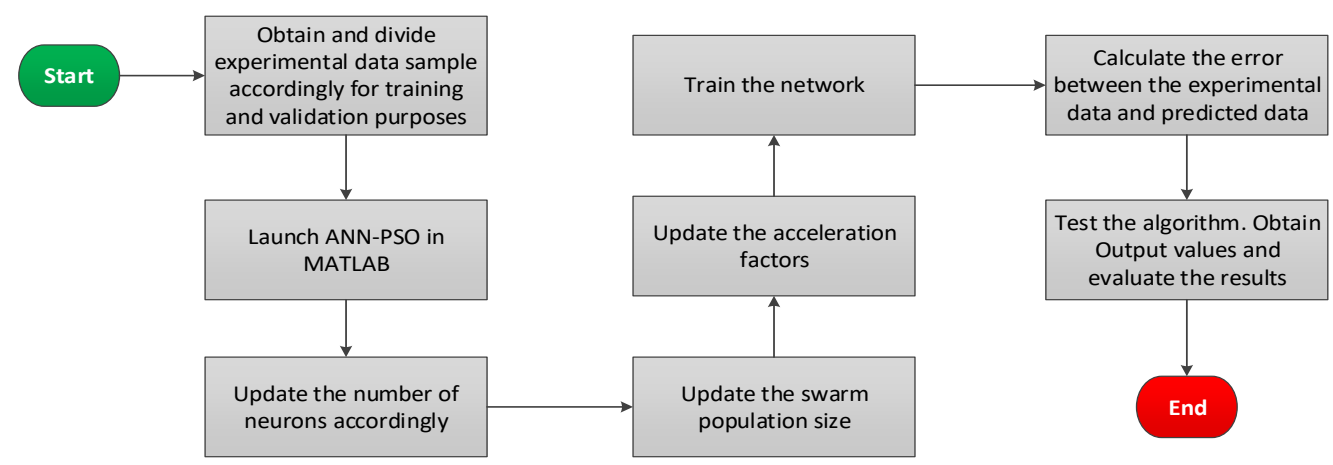

Figure 4. Proposed workflow for the methodology.

Table 1. Data samples extracted from Nsofor [18].

\begin{tabular}{|c|c|c|c|}
\hline Experiment No. & Frequency (Hz) & Mean Pressure (MPa) & OHTC $\left(\mathrm{W} / \mathrm{m}^{2} \mathrm{~K}\right)$ \\
\hline 1 & 300 & 0.3030 & 90.0000 \\
\hline 2 & 350 & 0.3030 & 79.0000 \\
\hline 3 & 400 & 0.3030 & 93.00 \\
\hline 4 & 450 & 0.3030 & 101.50 \\
\hline 5 & 300 & 0.4053 & 74.00 \\
\hline 6 & 350 & 0.4053 & 71.50 \\
\hline 7 & 400 & 0.4053 & 81.50 \\
\hline 8 & 450 & 0.4053 & 106.67 \\
\hline 9 & 300 & 0.5066 & 102.50 \\
\hline 10 & 350 & 0.5066 & 72.00 \\
\hline 11 & 400 & 0.5066 & 88.50 \\
\hline 12 & 450 & 0.5066 & 91.00 \\
\hline 13 & 300 & 0.6079 & 80.00 \\
\hline 14 & 350 & 0.6079 & 83.00 \\
\hline 15 & 400 & 0.6079 & 77.00 \\
\hline 16 & 450 & 0.6079 & 114.00 \\
\hline 17 & 300 & 0.7093 & 89.00 \\
\hline 18 & 350 & 0.7093 & 88.00 \\
\hline 19 & 400 & 0.7093 & 89.50 \\
\hline 20 & 450 & 0.7093 & 84.00 \\
\hline 21 & 300 & 0.8100 & 104.00 \\
\hline 22 & 350 & 0.8100 & 92.00 \\
\hline 23 & 400 & 0.8100 & 95.00 \\
\hline 24 & 450 & 0.81 & 107.5 \\
\hline
\end{tabular}

\section{Model Evaluation, Results, and Discussion}

The results of the AI models are discussed in the following section. The section is divided into four subsections. The first subsection discusses the ANN results, the second subsection discusses the ANFIS prediction results, the third subsection covers the impact of varying the parameters in the ANN-PSO model, and the fourth subsection shows a comparison of the performance of the three algorithms.

\subsection{Evaluation of ANN Model Prediction Performance}

We used the MATLAB "nntool" component with a backpropagation learning function to create the neural network, shown in Figure 5. The input and output targets were imported into MATLAB, and variables such as the performance function, the number of layers, and the number of neurons were selected accordingly. The epochs and max_fails parameters for the training of the network were altered and set at 44 to train the neural network. 


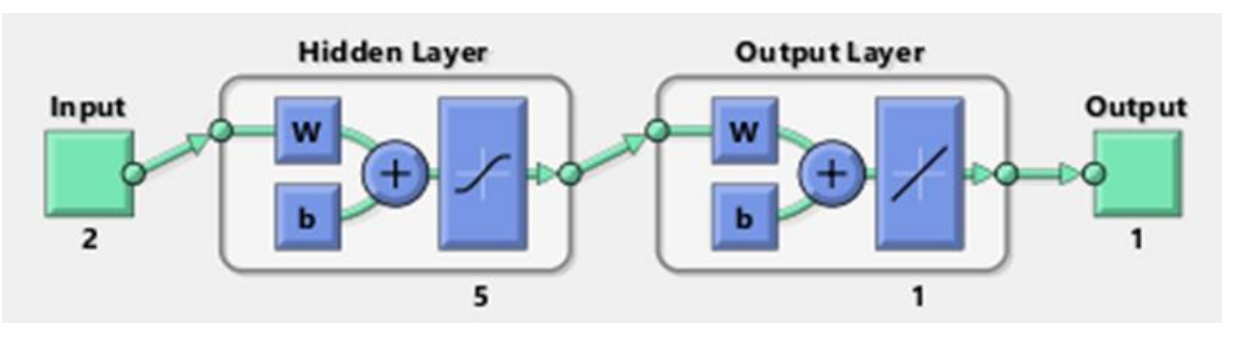

Figure 5. The structure of the neural network.

The network was trained, and the training, testing, and validation performance and overall data regression were generated, as shown in Figure 6. The overall regression value for the neural network was determined to be 0.80815 . This suggested that $80.8 \%$ of the data fit the regression model. Most researchers consider a regression value above 0.8 to be a good performance indicator.
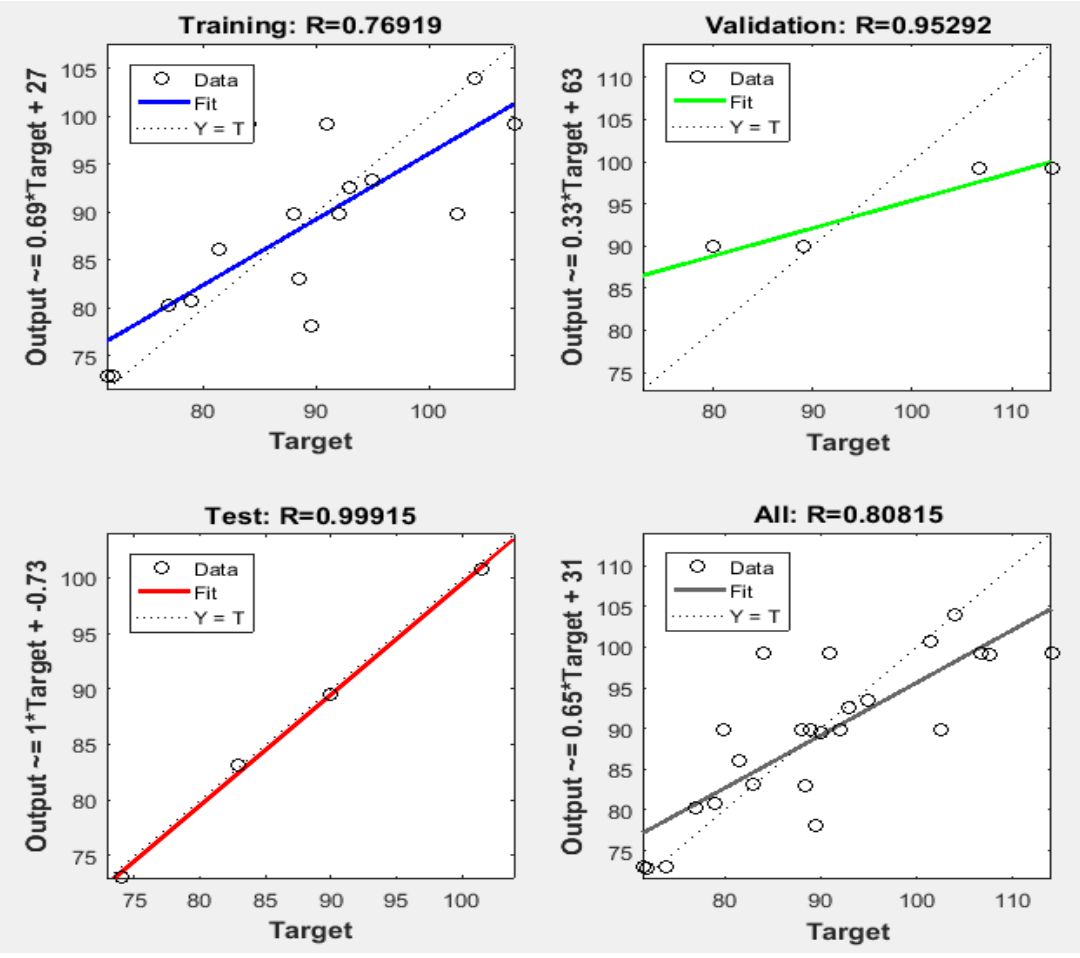

Figure 6. The training, validation, testing, and overall regression values.

Figure 7a displays the predicted values extracted from MATLAB's workspace vs. the experimental value. Figure 7a shows that the predicted values deviated by a small margin from the target values. This is quantified further in Figure $7 \mathrm{~b}$. The error percentage for each of the predicted values is shown in Figure $7 \mathrm{~b}$. The error \% of the values ranged from 0.49 to $12.73 \%$ for each of the predicted values. The $12.7 \%$ error was observed when predicting Experiment Number $19^{\prime}$ s target, while an error of $0.49 \%$ was obtained when predicting Experiment Number $1^{\prime}$ s target. 


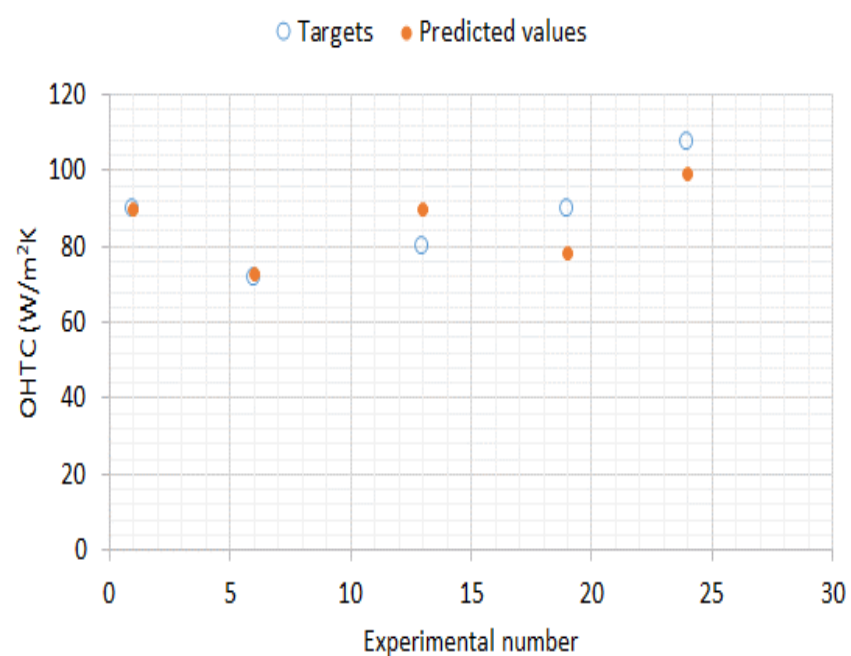

(a)

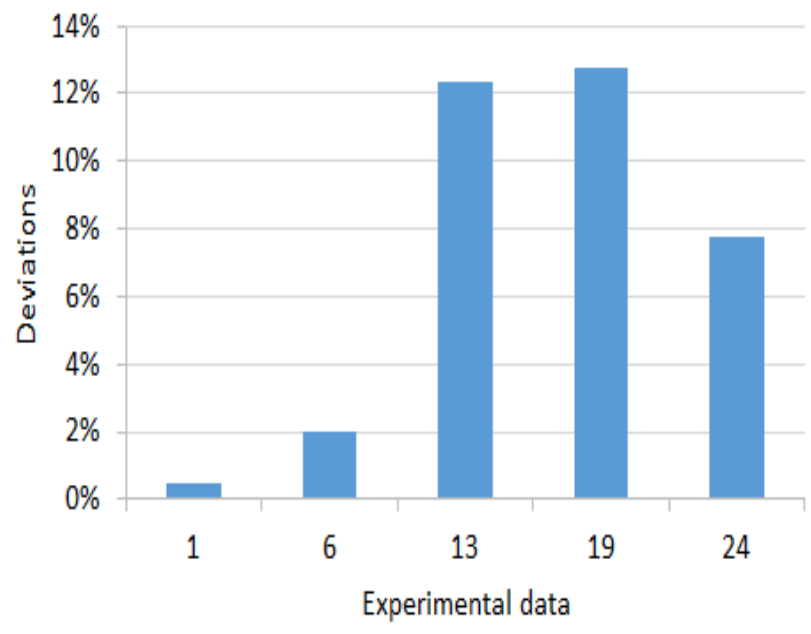

(b)

Figure 7. (a): Targeted values vs. the neural network predicted values. (b): Error \% calculated for each predicted point.

\subsection{ANFIS Prediction Performance}

The ANFIS network used in the work was extracted from MATLAB's toolbox. Figure 8 shows how the network was configured with the mean pressure and frequency set as the inputs and the oscillatory heat transfer coefficient set as the output function. Figures 9 and 10 show the membership function plots for the frequency and the mean pressure, respectively, with the alpha-cuts set from the input membership functions through the fuzzy inference rules.

Figure 11 shows the architecture of the input-output membership function. The structure demonstrates the logical operations that link the ANN and fuzzy inference for effective sensitivity via sigmoid function with well-structured rules.

Figure 12 represents the predicted values obtained from MATLAB's workspace for the ANFIS solution vs. the targeted values. This figure illustrates that the ANFIS predictions closely followed the targets. Figure 13 indicates the error \% between the predicted values and the targeted values. The discrepancies between the observed values were relatively small, with the deviations inferior to 1\%, except for Experiment Number 13 spiking to an error percentage of $8.2 \%$. Figure 14 shows the regression value to be 0.947 for the ANFIS network.

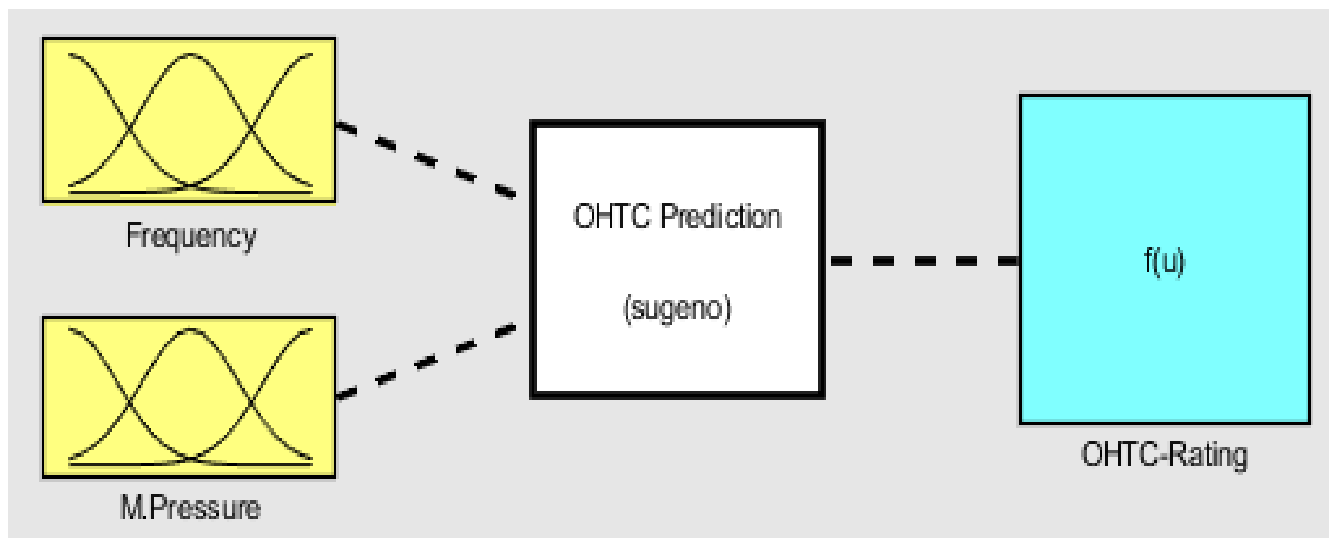

Figure 8. Input and output variables of the Sugeno FIS model. 


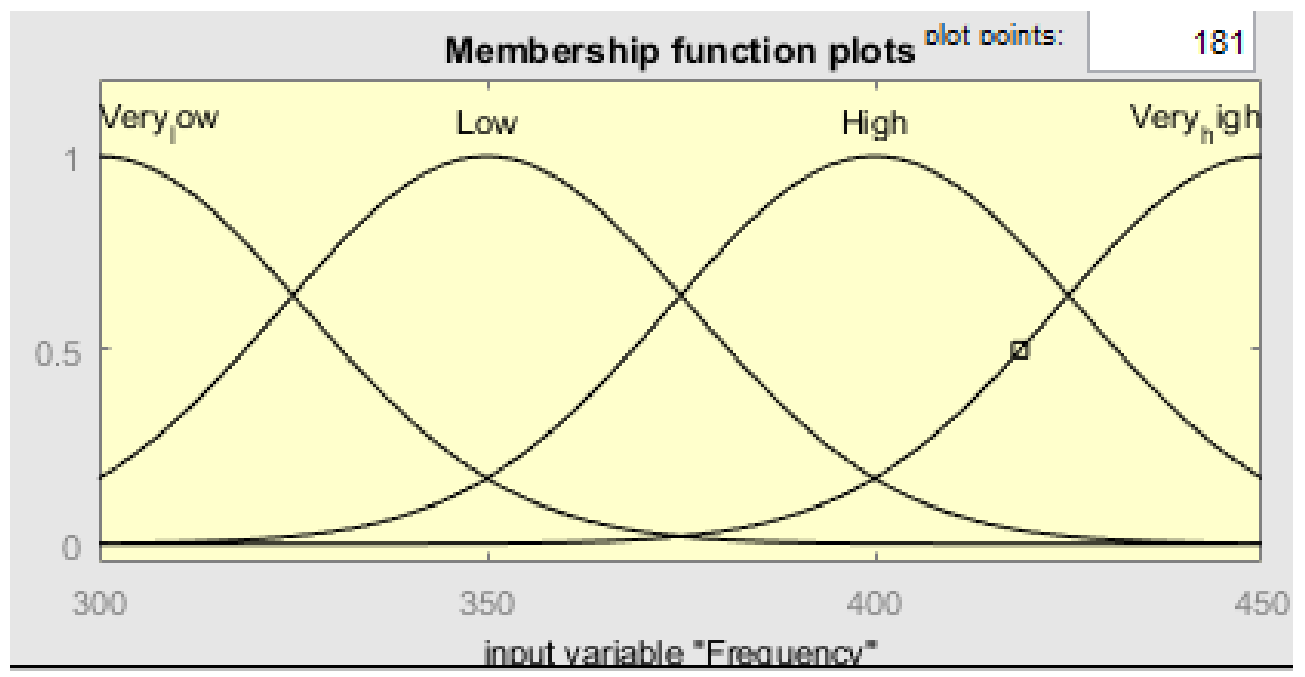

Figure 9. ANFIS membership function plot for the frequency.

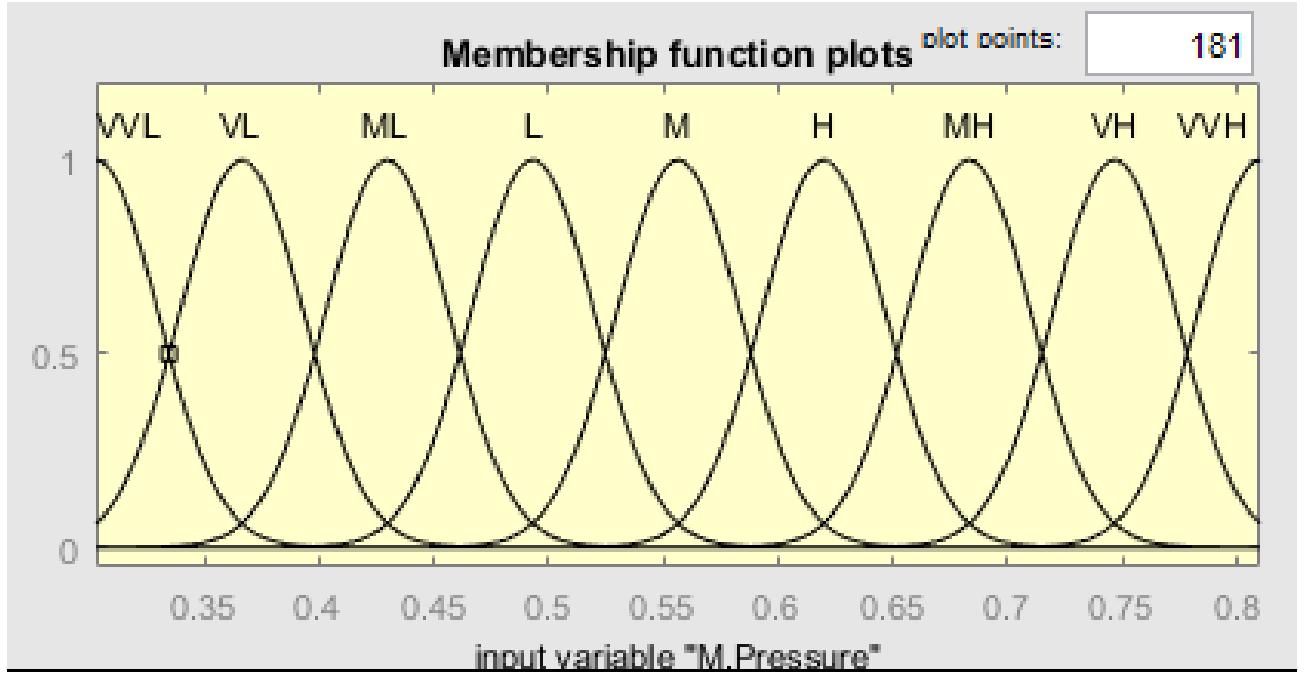

Figure 10. ANFIS membership function plot for the mean pressure.

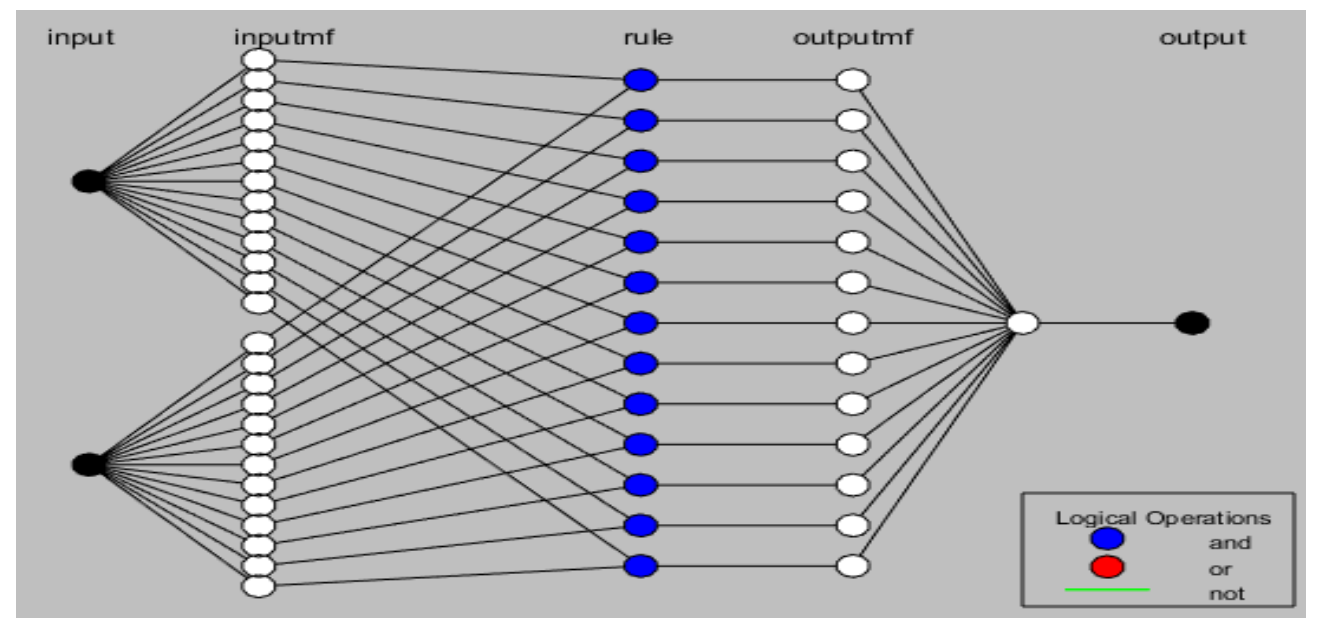

Figure 11. ANFIS architecture with input-output membership function. 


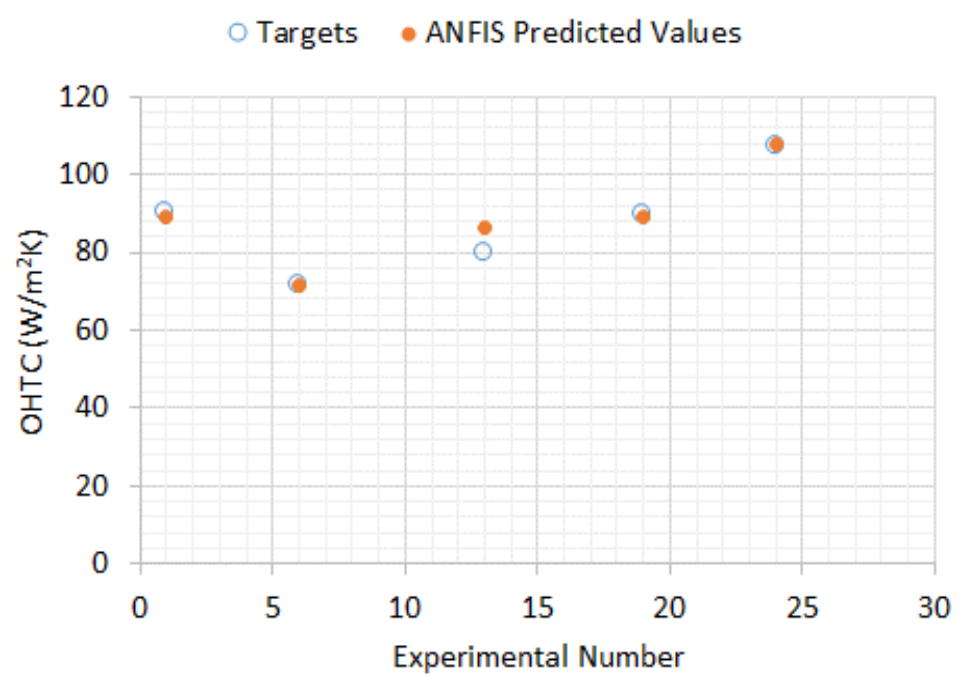

Figure 12. Targeted values vs. the ANFIS predicted values.

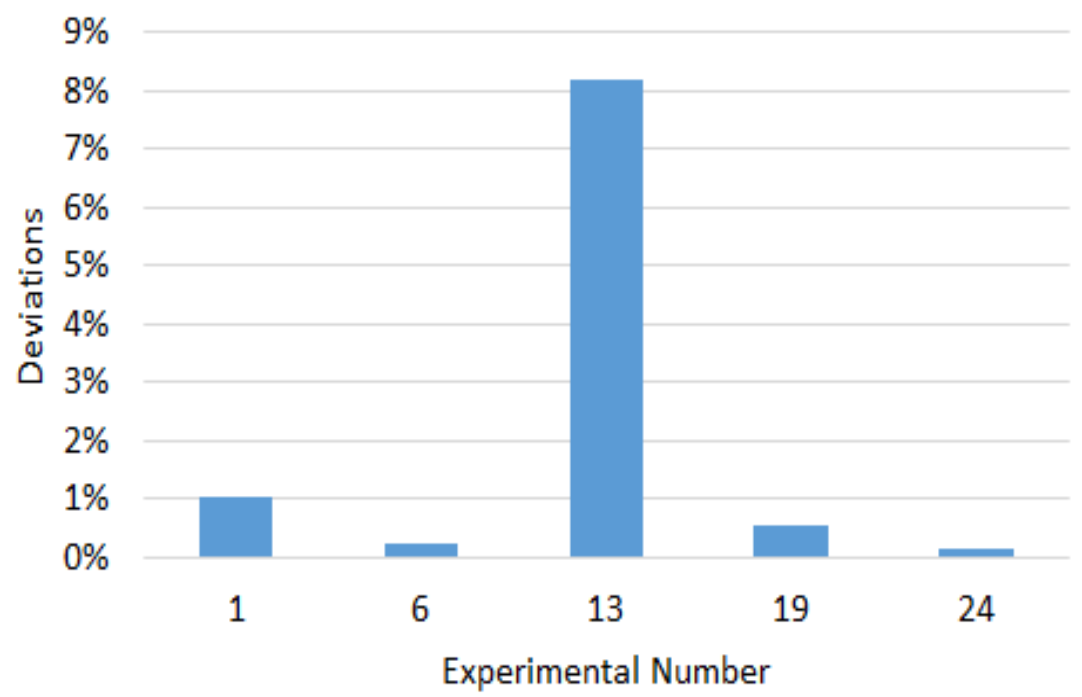

Figure 13. Error \% calculated for each predicted point for the ANFIS network.

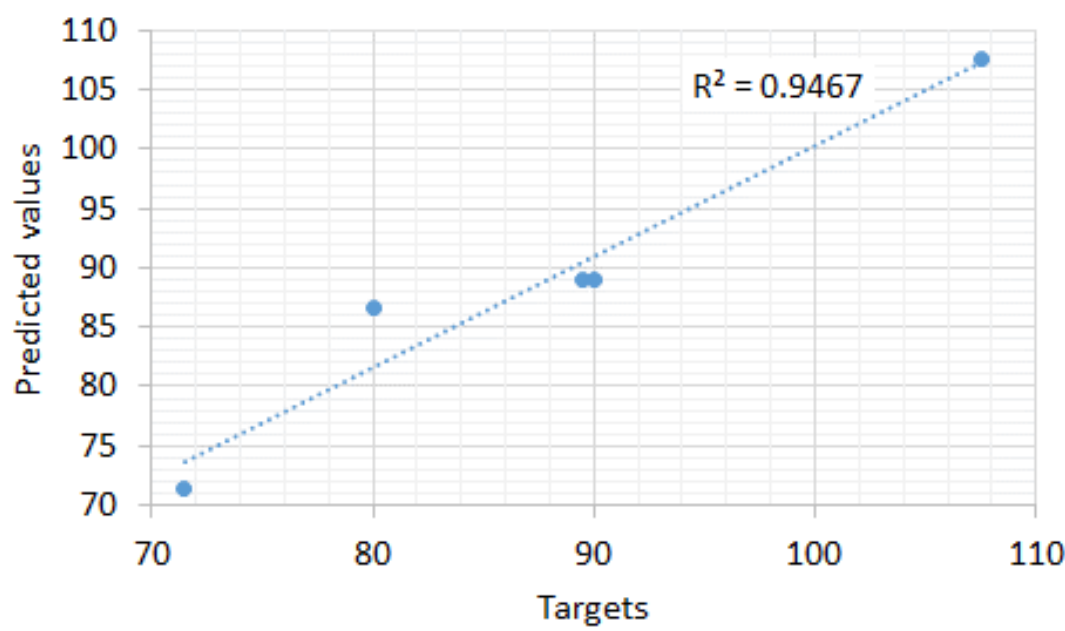

Figure 14. ANFIS regression value. 


\subsection{Evaluation of Constant Parameter in the ANN-PSO Model}

Table 2 represents the configurations of each ANN-PSO model, together with the MSE and $R^{2}$ results obtained for the prediction of the OHTC in a thermoacoustic refrigerator. The number of neurons, the swarm population, and the acceleration factor used for the ANN-PSO architecture were adjusted within the ranges 5-10, 10-200, and 1-3, respectively.

Table 2. ANN-PSO model configuration with model testing and training results.

\begin{tabular}{|c|c|c|c|c|c|c|}
\hline \multirow{2}{*}{ Number of Neurons } & \multirow{2}{*}{ Swarm Population } & \multicolumn{2}{|c|}{ Acceleration Factor } & \multirow{2}{*}{ Training $\mathbf{R}^{2}$} & \multirow{2}{*}{ MSE } & \multirow{2}{*}{ Testing $\mathbf{R}^{2}$} \\
\hline & & $\mathrm{C}_{1}$ & $\mathrm{C}_{2}$ & & & \\
\hline 5 & 10 & 2.25 & 2 & 0.8136 & 296.53 & 0.7429 \\
\hline 5 & 20 & 2.25 & 2 & 0.8104 & 142.89 & 0.0050 \\
\hline 5 & 50 & 1.5 & 2.25 & 0.7542 & 142.89 & 0.0050 \\
\hline 5 & 100 & 1 & 2.75 & 0.7981 & 178.39 & 0.0496 \\
\hline 5 & 200 & 1.5 & 2 & 0.8123 & 172.83 & 0.0451 \\
\hline 5 & 400 & 1 & 2.25 & 0.8283 & 419.316 & 0.0023 \\
\hline 6 & 10 & 1 & 3 & 0.7999 & 157.39 & 0.7865 \\
\hline 6 & 20 & 2 & 2.25 & 0.7523 & 22.81 & 0.2234 \\
\hline 6 & 50 & 1 & 2.5 & 0.8027 & 67.56 & 0.0313 \\
\hline 6 & 100 & 1 & 2.5 & 0.8331 & 249.02 & 0.0040 \\
\hline 6 & 200 & 1 & 2.75 & 0.7982 & 141.39 & 0.0874 \\
\hline 6 & 400 & 1 & 2.25 & 0.8284 & 493.01 & 0.0015 \\
\hline 7 & 10 & 1.5 & 2.5 & 0.8518 & 15.65 & 0.8090 \\
\hline 7 & 20 & 1 & 2.75 & 0.8203 & 162.06 & 0.0667 \\
\hline 7 & 50 & 1 & 2.5 & 0.8056 & 136.45 & 0.0383 \\
\hline 7 & 100 & 1 & 2.5 & 0.8425 & 293.02 & 0.0454 \\
\hline 7 & 200 & 1.5 & 2.25 & 0.8372 & 160.17 & 0.0286 \\
\hline 7 & 400 & 1 & 2.25 & 0.83105 & 267.12 & 0.0274 \\
\hline 8 & 10 & 1 & 2.75 & 0.8450 & 25.21 & 0.8249 \\
\hline 8 & 20 & 1 & 2.5 & 0.8672 & 383.28 & 0.0025 \\
\hline 8 & 50 & 1.5 & 2.25 & 0.8512 & 388.17 & 0.0236 \\
\hline 8 & 100 & 1 & 2.5 & 0.8408 & 243.77 & 0.0042 \\
\hline 8 & 200 & 1 & 2.75 & 0.8685 & 474.42 & 0.0117 \\
\hline 9 & 10 & 1 & 2.75 & 0.8526 & 4.56 & 0.8125 \\
\hline 9 & 20 & 1 & 3 & 0.8191 & 191.09 & 0.0055 \\
\hline 9 & 50 & 1.5 & 2.25 & 0.8595 & 628.58 & 0.0002 \\
\hline 9 & 100 & 2 & 2 & 0.8615 & 277.09 & 0.0276 \\
\hline 9 & 200 & 1.5 & 2.25 & 0.8286 & 211.10 & 0.0889 \\
\hline 10 & 10 & 1 & 2.75 & 0.8434 & 115.71 & 0.9017 \\
\hline 10 & 20 & 1.5 & 2.5 & 0.8415 & 273.12 & 0.0000 \\
\hline 10 & 50 & 1.5 & 2.5 & 0.8520 & 279.65 & 0.0037 \\
\hline 10 & 100 & 1 & 2.75 & 0.8650 & 572.84 & 0.2003 \\
\hline 10 & 200 & 1 & 2.75 & 0.8627 & 316.33 & 0.0219 \\
\hline
\end{tabular}

The best training result was obtained when using the configuration with 10 neurons, with a swarm population size of 10 , and $C_{1}$ and $C_{2}$ acceleration factors of 1.5 and 2.75, respectively. The corresponding training $\mathrm{R}^{2}$, MSE, and testing $\mathrm{R}^{2}$ values for the models were found to be $0.84,115.71$, and 0.92 , respectively. The best performing testing result was obtained when using the configuration with 8 neurons, with a swarm population size of 200 , and $C_{1}$ and $C_{2}$ accelerations of 1 and 2.75, respectively. The corresponding training $\mathrm{R}^{2}$ and MSE were found to be 0.868 and 474.42 . The literature has established that for a model to be considered accurate, the $\mathrm{R}^{2}$ value must be closer to 1 . Since the model with 10 neurons exhibited a value above 0.8 for both the training and testing regression, this architecture was used for comparison with the other soft computing techniques.

For a more expressive comparison of the prediction values, the output values were plotted against the targeted experimental values in Figure 15. Figure 16 shows the absolute error percentage. This plot shows the difference between the targeted values and the predicted values. The average absolute error percentage for the 10 neuron model was $13 \%$. 


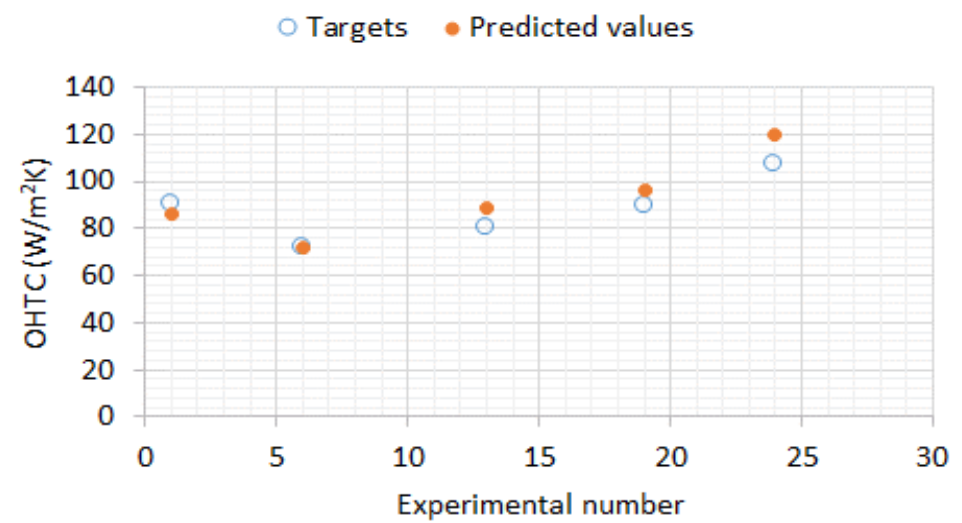

Figure 15. ANN-PSO predicted values (10 Neurons/10 Swarm) vs. targeted values.

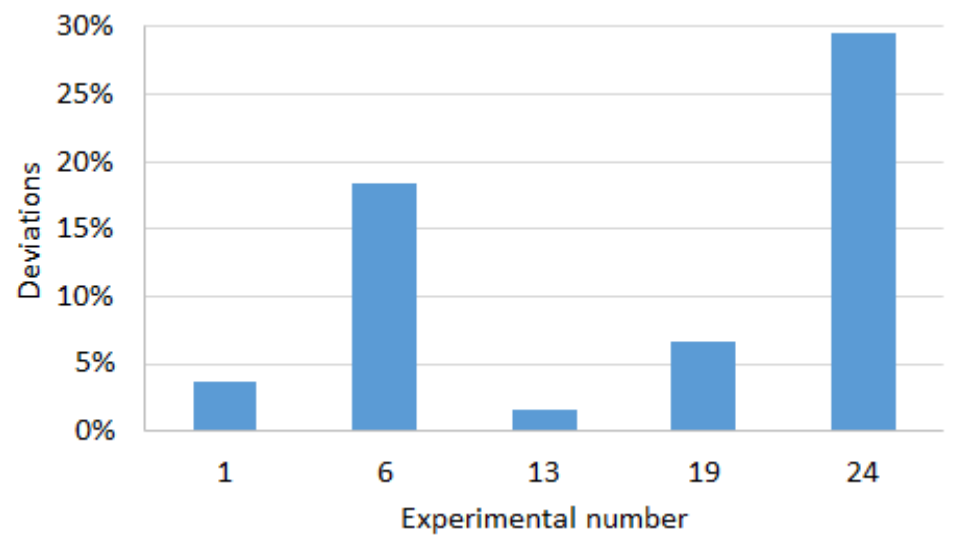

Figure 16. Absolute error $\%$ of predictions for the best performing ANN-PSO configurations.

\section{A Comparison of the Prediction Performance of ANN, ANN-PSO, ANFIS}

The performances of ANN, ANN-PSO, and ANFIS are compared in this subsection. Table 3 details a summary of the results, tabulating the regression value and average error $\%$ for the three algorithms. Figure 17 shows the predicted values of the ANN, ANN-PSO, and ANFIS plotted against the target value, and Figure 18 shows a plot comparing the error percentages of the three models. Both Table 3 and Figure 17's plot indicate that the OHTC values predicted by the ANFIS model were a better fit to the target than the ANN and ANN-PSO OHTC values.

Table 3. Regression values for ANN, ANN-PSO and ANFIS.

\begin{tabular}{ccc}
\hline & $\mathbf{R}^{\mathbf{2}}$ (Training/Testing) & Average Error $\%$ \\
\hline ANN & $0.769 / 0.999$ & $7 \%$ \\
ANN-PSO & $0.843 / 0.9017$ & $13 \%$ \\
ANFIS & 0.9467 & $2 \%$ \\
\hline
\end{tabular}




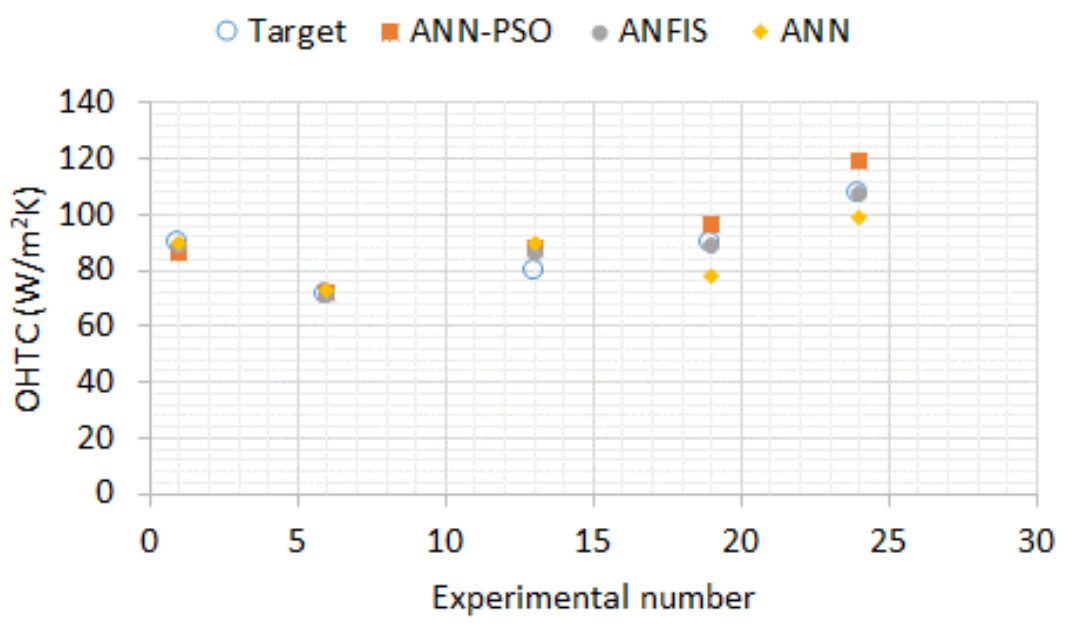

Figure 17. Output values for ANN, ANN-PSO, and ANFIS vs. the targeted value.

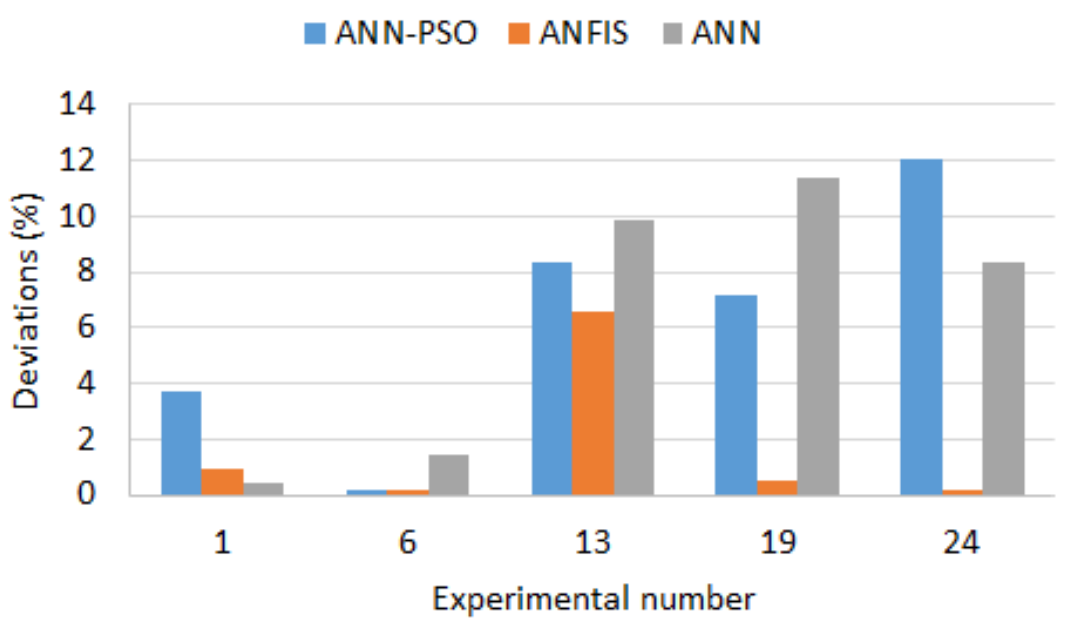

Figure 18. A Plot comparing the ANN, ANN-PSO, and ANFIS error percentages.

\section{Conclusions}

In this paper, several approaches were proposed to effectively model and analyse the oscillatory heat transfer coefficient of thermoacoustic refrigerators. Twenty-four (24) data samples obtained from an existing publication were considered. Three models were developed and analysed to predict the OHTC, namely, the ANN, ANN-PSO, and ANFIS models. A comparison study was carried out to assess the prediction performance of the networks using the regression value. The study showed that the ANFIS model had superior prediction performance compared to the ANN and ANN-PSO models. A parametric analysis was performed to identify the best architecture of the ANN-PSO model, which depended on the number of neurons, the swarm population size, and the acceleration factors. The $\mathrm{R}^{2}$ and the MSE were used to measure the prediction performance of each ANN-PSO configuration. The results indicated that the ANN-PSO parameters affected the prediction performance of the model. The best training result was obtained when using the configuration with 10 neurons, with a swarm population size of 10 , and $C_{1}$ and $C_{2}$ accelerations of 1 and 2.75, respectively. The corresponding training $R^{2}, M S E$, and testing $\mathrm{R}^{2}$ values were found to be $0.84,115.71$, and 0.92 , respectively. The best testing result was obtained when using the configuration with 8 neurons, with a swarm population size of 200 , and $C_{1}$ and $C_{2}$ accelerations of 1 and 2.75, respectively. The corresponding training $\mathrm{R}^{2}$ value was found to be 0.868 . This study reveals that the performance characteristics of the thermoacoustic device can be analysed after conducting numerous tests on several configurations to measure the oscillatory heat transfer coefficient. The use of soft computing techniques for the prediction of the oscillatory heat transfer coefficient, illustrated in this 
study, showed that a limited number of configurations can be tested, and henceforth the performance characteristics of other configurations can be predicted with a higher level of accuracy. This approach will minimise time-consuming and costly experiments and assist decision makers in identifying the configuration that achieves the highest performance of thermoacoustic systems.

Author Contributions: Conceptualization, M.M. and L.T.; methodology, M.M.; software, M.M.; validation, M.M., L.T. and M.O.; formal analysis, M.M.; investigation, M.M.; resources, L.T.; data curation, M.M.; writing—original draft preparation, M.M.; writing—review and editing, L.T. and M.O.; visualization, M.O.; supervision, L.T.; project administration, L.T.; funding acquisition, L.T. All authors have read and agreed to the published version of the manuscript.

Funding: The APC was funded by the University of Johannesburg.

Institutional Review Board Statement: Not applicable.

Informed Consent Statement: Not applicable.

Data Availability Statement: Not applicable.

Conflicts of Interest: The authors declare no conflict of interest.

\section{References}

1. Shivakumara, N.V.; Arya, B. Performance evaluation of $10 \mathrm{~W}$ cooling power thermoacoustic refrigerator with spiral stacks using air and helium as working fluids. Eng. Res. Express 2020, 2, 015032.

2. Mishra, S.; Dhairya, S. A review on thermoacoustic refrigeration system. Int. J. Innov. Res. Technol. 2019, 6, 148590.

3. Rahman, A.A.; Zhang, X. Single-objective optimization for stack unit of standing wave thermoacoustic refrigerator through fruit fly optimization algorithm. Int. J. Refrigerat. 2019, 98, 35-41. [CrossRef]

4. Rahman, A.A.; Zhang, X. Prediction of acoustic wave parameters of thermoacoustic prime mover through artificial neural network technique: Practical approach for thermoacoustics. Therm. Sci. Eng. Prog. 2018, 8, 257-268. [CrossRef]

5. Abd Elaziz, M.; Elsheikh, A.H.; Sharshir, S.W. Improved prediction of oscillatory heat transfer coefficient for a thermoacoustic heat exchanger using modified adaptive neuro-fuzzy inference system. Int. J. Refrigerat. 2019, 102, 47-54. [CrossRef]

6. Machesa, M.G.K.; Tartibu, L.K.; Tekweme, F.K.; Okwu, M.O. Prediction of oscillatory heat transfer coefficient in heat exchangers of thermo-acoustic systems. In Proceedings of the International Mechanical Engineering Congress and Exposition, Salt Lake City, UT, USA, 11-14 November 2019.

7. Bensoin, E.; Knio, O.M. Numerical study of thermoacoustic heat exchangers in the thin plate limit. Num. Heat Transf. Part A Appl. 2001, 40, 455-471.

8. Matveev, K.I.; Swift, G.W.; Backhaus, S. Analytical solution for temperature profiles at the ends of thermal buffer tubes. Int. J. Heat Mass Transf. 2007, 50, 897-901. [CrossRef]

9. Paek, I.; Braun, J.E.; Mongeau, L. Characterizing heat transfer coefficients for heat exchangers in standing wave thermoacoustic coolers. J. Acoust. Soc. Am. 2005, 118, 2271-2280. [CrossRef]

10. Wakeland, R.S.; Keolian, R.M. Effectiveness of parallel-plate heat exchangers in thermoacoustic devices. J. Acoust. Soc. Am. 2004, 115, 2873-2886. [CrossRef]

11. Tang, K.; Yu, J.; Jin, T.; Wang, Y.; Tang, W.; Gan, Z. Heat transfer of laminar oscillating flow in finned heat exchanger of pulse tube refrigerator. Int. J. Heat Mass Transf. 2014, 70, 811-818. [CrossRef]

12. Alamir, M.A. An artificial neural network model for predicting the performance of thermoacoustic refrigerators. Int. J. Heat Mass Transf. 2021, 164, 120551. [CrossRef]

13. Saat, F.A.M.; Jaworski, A.J. Oscillatory flow and heat transfer within parallel-plate heat exchangers of thermoacoustic systems. In Proceedings of the World Congress on Engineering 2013-Lecture Notes in Engineering and Computer Science, London, UK, 3-5 July 2013; Volume 3, pp. 1699-1704.

14. Hofler, T.J. Thermoacoustic Refrigerator Design and Performance (Heat Engine, Resonator, Microphone). Ph.D. Thesis, University of California, San Diego, CA, USA, 1986.

15. Tijani, M.E.H.; Zeegers, J.C.H.; De Waele, A.T.A.M. Construction and performance of a thermoacoustic refrigerator. Cryogenics 2002, 42, 59-66. [CrossRef]

16. Tijani, M.E.H.; Zeegers, J.C.H.; De Waele, A.T.A.M. Design of thermoacoustic refrigerators. Cryogenics 2002, 42, 49-57. [CrossRef]

17. Freund, S. Local Heat Transfer Coefficients Measured with Temperature Oscillation IR Thermography. Ph.D. Theisis, Helmut Schmidt University, Hamburg, Germany, 2008.

18. Nsofor, E.C.; Celik, S.; Wang, X. Experimental study on the heat transfer at the heat exchanger of the thermoacoustic refrigerating system. Appl. Therm. Eng. 2007, 27, 2435-2442. [CrossRef]

19. Youssef, A.; El-Telbany, M.; Zekry, A. The role of artificial intelligence in photo-voltaic systems design and control: A review. Renew. Sustain. Energy Rev. 2017, 78, 72-79. [CrossRef] 
20. Mumith, J.A.; Karayiannis, T.; Makatsoris, C. Design and optimization of a thermoacoustic heat engine using reinforcement learning. Int. J. Low Carbon Technol. 2016, 11, 431-439. [CrossRef]

21. Rao, J.; Raju, R. Using a generalized regression neural network prediction tool to estimate thermal performance in a heat exchanger by using triple elliptical leaf angle strips with opposite orientation and same direction. Int. J. Innovat. Technol. Explor. Eng. 2019, 8, 528-535.

22. Wang, K.; Sun, D.; Zhang, J.; Xu, Y.; Luo, K.; Zhang, N.; Zou, J.; Qiu, L. An acoustically matched traveling-wave thermoacoustic generator achieving $750 \mathrm{~W}$ electric power. Energy 2016, 103, 313-321. [CrossRef]

23. Abdelrahman, A.M.; Zhang, X. Artificial Neural Network-DeltaEC Hybrid Model for Thermoacoustic Systems: New Synergistic Approach. J. Acoust. Soc. Am. 2018, 144, 1714. [CrossRef]

24. Alam, M. Codes in MATLAB for Training Artificial Neural Network Using Particle Swarm Optimization. Res. Gate 2016, 1-16. Available online: https://www.researchgate.net/publication/305325563_Codes_in_MATLAB_for_Training_Artificial_Neural_ Network_using_Particle_Swarm_Optimization (accessed on 12 September 2019). 